\title{
Shelter Utilization by the Molluscan Cephalopod Octopus bimaculatus
}

\author{
Richard F. Ambrose \\ Department of Biology, University of California, Los Angeles, California 90024, USA
}

\begin{abstract}
Octopus bimaculatus, a common member of subtidal and intertidal communities of southern California (USA), is found in a wide range of habitats at Santa Catalina Island, where it is equally abundant in holes, under rocks, and in crevices. Although shelters may be scarce in some areas, it appears that shelters generally do not limit the size of $O$. bimaculatus populations. Shelters suitable for habitation by adult and juvenile $O$. bimaculatus were always in excess during this study. Nearly half of the population studied inhabited their shelter for more than a month, and a few octopuses occupied the same shelter for at least 5 months. One fourth of the population spent less than a week in the same shelter, and many of these may have changed shelters every day. However, nearly all octopuses remained in the same area. The nontransient behavior of $O$. bimaculatus may have important implications for resource utilization, mating and agonistic behavior
\end{abstract}

\section{INTRODUCTION}

The two-spotted octopus, Octopus bimaculatus Verrill 1883 , is a common member of the subtidal and intertidal communities of southern California. $O$. bimaculatus consumes many crustacean and molluscan prey species, and its predation can result in the reduction or elimination of local populations of several species of gastropods and bivalves (Fotherington, 1974; Schmitt, 1979). In southern California intertidal regions $O$. bimaculatus predation has strongly influenced the lower distribution of the gastropod Tegula funebralis (and by inference, other gastropod species; Fawcett, 1979) and the activity patterns of the limpets Collisella limatula and C. scabra (Wells, 1980).

The specific effect of octopus predation on prey species populations could be influenced by the pattern of octopus shelter utilization. An octopus shelter provides refuge from predation, a site for egg-laying, and perhaps a base for agonistic interactions or foraging forays. Most benthic octopuses utilize shelters, but little has been published on the nature of octopus shelters or patterns of shelter utilization.

Observations on Octopus vulgaris, $O$. briareus, and $O$. cyanea indicate that octopuses generally reside in holes under rocks, in reefs, or in man-made articles such as beer bottles, cans, and pipes (van Heukelem, 1966; Altman, 1967; Legac, 1969; Hochberg and
Couch, 1971; Wolterding, 1971). Van Heukelem (1966) reported that $O$. cyanea in Hawail may occupy the same shelter for up to $35 \mathrm{~d}$. In the Mediterranean Sea, most $O$. vulgaris studied by Kayes (1974) occupied holes for only 1 or $2 \mathrm{~d}$, although some individuals occupied the same shelter for nearly 2 weeks. Observations on marked octopuses indicated that short term occupations were due to octopuses changing homes within the study area rather than large scale immigrations and emigrations (Kayes, 1974). MacGinitie (1938) believed $O$. bimaculatus to have a permanent shelter but did not specify the nature or extent of his observations; furthermore, his observations were probably limited to intertidal populations.

This paper describes the characteristics of shelters occupied by undisturbed subtidal Octopus bimaculatus in their natural habitat, and discusses 2 major aspects of $O$. bimaculatus shelter utilization: (1) shelter abundance, and (2) length of shelter residence. These aspects may be of considerable importance in determining the effect octopus predators have in their community.

\section{METHODS}

Research was conducted on Santa Catalina Island $\left(33^{\circ} 27^{\prime} \mathrm{N}, 118^{\circ} 29^{\prime} \mathrm{W}\right)$ at the Catalina Marine Science 
Center, about $30 \mathrm{~km}$ south of Los Angeles, California, USA. A permanent study site was established at Bird Rock, a small island $0.5 \mathrm{~km}$ off the north (leeward) side of Santa Catalina Island; several other areas off Santa Catalina Island are also included in portions of this study. Habitats surveyed vary from sandy bottoms to rocky substrates with an algal understory and kelp (Macrocystis pyrifera) forest.

Octopuses were observed in their natural environment using SCUBA equipment. Although Octopus bimaculatus is reported to occur up to depths of $50 \mathrm{~m}$ (Hochberg and Fields, 1980), during this study it was rarely found deeper than $15 \mathrm{~m}$. Octopuses have been reported from $30 \mathrm{~m}$ at Bird Rock (A. Lissner and $\mathrm{K}$. Behrents, pers. comm.); repeated searches to these depths around Santa Catalina Island have revealed only a few individuals as deep as $20 \mathrm{~m}$.

Data on shelter type (crevice, hole, under rocks) and substrate (bedrock, boulders, sand, etc.) were collected for nearly every octopus encountered (104) between May and November 1977. I attempted to collect data equitably among areas, but because it is difficult to expend equal efforts searching for octopuses in each habitat type, the data on shelter types and substrates should be viewed as close approximations.

To estimate the general availability of octopus shelters, the abundance of potential shelters was measured at 14 different locations on the lee side of Santa Cataline Island (Fig. 1; shelter density was not measured at Site 11, so that site is excluded from these analyses). The study sites are representative of the types of shallow subtidal rocky reef habitats available at the island; they were chosen without regard to the abundances of shelters or octopuses. All sites are relatively protected horizontal reefs in less than $10 \mathrm{~m}$ of water. Shelter abundances were quantified by counting all potential shelters within $1 \mathrm{~m}$ of a $10 \mathrm{~m}$ transect line; 2 or 3 transects were run at each site. The decision to consider a crevice or hole as a potential shelter was admittedly subjective, but my judgement was based on observations of hundreds of octopuses and their shelters over a 5 year period. Although the estimated number of shelters may not be absolutely correct, I believe it is accurate enough for comparative purposes.

Octopus density was measured at each site by searching carefully and systematically for $30 \mathrm{~min}$ on one side of a $20 \mathrm{~m}$ transect line. The number of Octopus bimaculatus was recorded and the area searched was determined for calculation of octopus density. The habitat was searched very thoroughly, but in a non-destructive manner, so that some individuals may have been overlooked; furthermore, substrate type probably influenced the efficiency of observing octopuses. These potential inaccuracies are somewhat ameliorated by the tendency for octopuses to sit at the

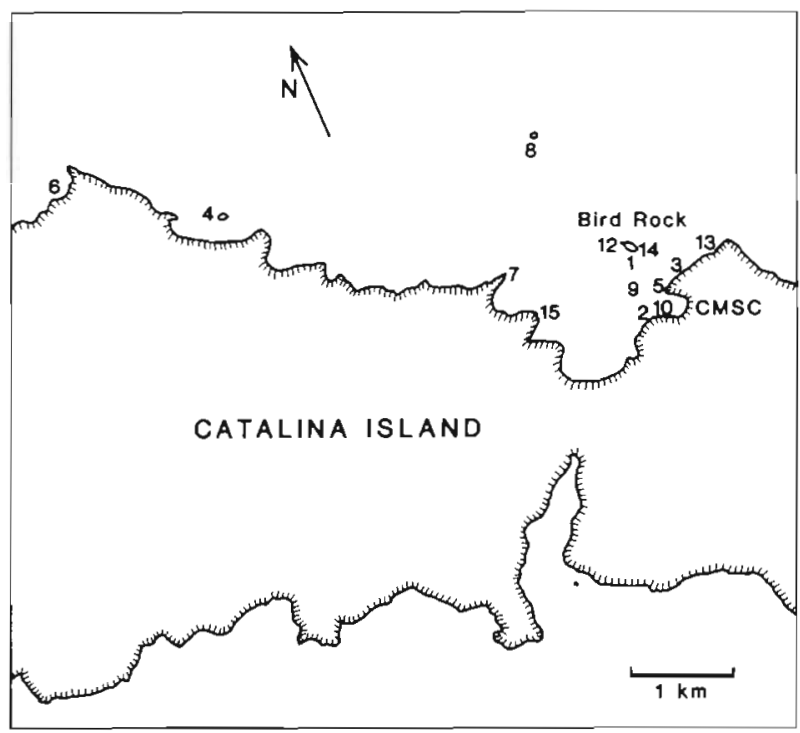

Fig. 1. Location of subtidal rocky reef study sites at Santa Catalina Island, California, USA. Numbers correspond to site numbers in Table 1

entrance to their shelters when not active (pers. obs.). Octopuses are primarily active at night; all censuses were taken during the day.

Each hole and crevice occupied by an octopus at the Bird Rock study site was permanently marked with a lettered tag. This procedure was repeated until octopuses in unmarked shelters were rarely found, indicating that most suitable shelters had been marked. Censuses of the octopuses at Bird Rock were made during which known and potential locations of octopus shelters were studied intensively and the location of each octopus recorded. Additional reconnaissance confirmed that most octopuses in the study site were included in each census.

Shelter abundance was estimated by determining the number of different shelters occupied in censuses between July 1977 and March 1979. During this period 923 occupancies were recorded for 48 censuses. Since some shelters may have been used as a temporary refuge only, not all of the shelters recorded may have been suitable for residency. A suitable shelter was therefore considered to be one which was occupied on 4 or more different censuses.

The length of shelter residence was estimated on the basis of runs, defined as the number of consecutive (roughly weekly) censuses a shelter was occupied between 15 August and 28 November, 1978. The proportion of nonbrooding octopuses occupying shelters for runs of different lengths (i.e. 1 week, 2 weeks, and so on up to the maximum length observed) was determined for each of the 14 census periods. To elucidate the general pattern of shelter residence, the average of these proportions was calculated for each length run. 
Shelters that were occupied for $\geq 4$ consecutive censuses are considered to be permanent residences. During this period the Bird Rock octopus population varied from 11 to 44 octopuses. Daily censuses were made for several periods to evaluate the short-term movements of the population.

Several indirect lines of evidence indicate that the census gives a relatively accurate measure of length of shelter occupancy. Octopuses in some holes could be individually identified by scars; more frequently octopus size and/or unique behavior identified individuals. Certain isolated shelters were unoccupied for long periods of time, then occupied continuously by an octopus. Occupied shelters are characteristically 'neat and clean', and lack of occupancy is usually noticeable within a few days by the accumulation of debris

One drawback to the use of census data to elucidate the length of shelter residence is the relatively long intercensus interval. A long-term resident could have been absent for only a short time (e.g. while foraging) during a census and the shelter recorded as unoccupied. The probability of this occurrence is minimized because few octopuses forage during the day, when all censuses were taken. Likewise, a resident octopus could have been absent for several days without its absence being recorded. Nonetheless, the general pattern of shelter residency presented here is likely to be accurate if not precise.

Some octopuses were individually marked to corroborate evidence on shelter occupancy from the Bird Rock censuses. In August 1977, 18 octopuses were marked with garment tags. The tagging operation apparently traumatized the octopuses and many were not resighted. Furthermore, tags usually remain attached to an octopus for only a few days.

Octopuses were also marked by subcutaneous injections of vital dyes (nile blue and rose bengal) in distinctive patterns on the anterior dorsal edge of the first pair of arms (Hochberg and Couch, 1971; Kayes, 1974). permitting subsequent identification of individual octopuses still in their shelters. Fifteen octopuses were marked in this manner at the west end of Bird Rock in October and November 1978, 4 of which were resighted a total of eight times.

\section{RESULTS}

\section{SheIter Characteristics}

Octopus bimaculatus were found in virtually all habitat types at Catalina. Most of the 104 octopuses seen in the survey occurred in kelp forests (46\%) and rock walls $(20 \%)$. A slight preference for kelp forests may exist, but this possibility cannot be confirmed since habitat availability was not quantified. Octopus shelters were found more frequently in bedrock or boulders $(79 \%)$ than any other type of substrate; octopuses were also found in sand (4\%), rubble (7\%), and rocks on sand (8\%).

Shelter characteristics were quite variable, but 3 major types of shelters were distinguished: holes, under rocks, and crevices. Hole shelters had welldefined boundaries with an entrance either equal to or less than the largest diameter of the hole. Two hole shelters $(2 \%)$ were the only shelters surveyed which had multiple entrances. Crevice shelters often had entrances that were wider than high, with interior dimensions of the crevice equal to or smaller than the entrance; shelter boundaries were often difficult to determine due to the lateral extent of the crevice. Shelters under rocks had either hole-like or crevicelike characteristics. Overall, octopuses were equally common in all 3 shelter types. The proportion of the population in each type varied from location to location according to the availability of each shelter type. Octopuses at Bird Rock were found in crevice shelters 60 to $90 \%$ of the time. However, Bird Rock contains a vast network of cracks in the underlying bedrock, and shelters of other types are scarce.

On a number of occasions octopuses were observed to dig or blow out shelters. This is accomplished by a combination of jets of water directed forcefully at the sand and movement of sand by suckers, arms, and web. Excavated sand is dispersed by forceful jets of water. The process is quite rapid, and a hole up to $20 \mathrm{~cm}$ deep may be dug in a matter of minutes. All observed cases of digging involved cracks in bedrock which were filled with sand and shelly debris; shelters are also dug in sand. I have not observed complete shelter construction, but some shelter modification such as moving loose stones or debris seems to be universal.

\section{Shelter Abundance}

Adult Octopus bimaculatus at the Bird Rock study site were found in 204 different shelters between July 1977 and March 1979. The number of times a single shelter was occupied ranged from 1 to 24 (Fig. 2). Eighty-seven shelters were 'suitable' by the criterion of being occupied on 4 or more different censuses. These shelters accounted for $80 \%$ of the total occupancies observed (923) during the study period.

The abundance of potential shelters varied considerably among the 14 sites studied, ranging from 0.7 shelters $10 \mathrm{~m}^{-2}$ at Site 1 to over 40 times that density at Site 15 (Table 1). The Bird Rock study site (Site 14) had the second lowest shelter density, 3.0 shelters $10 \mathrm{~m}^{-2}$.

Octopus abundances for the 14 sites are also given in 


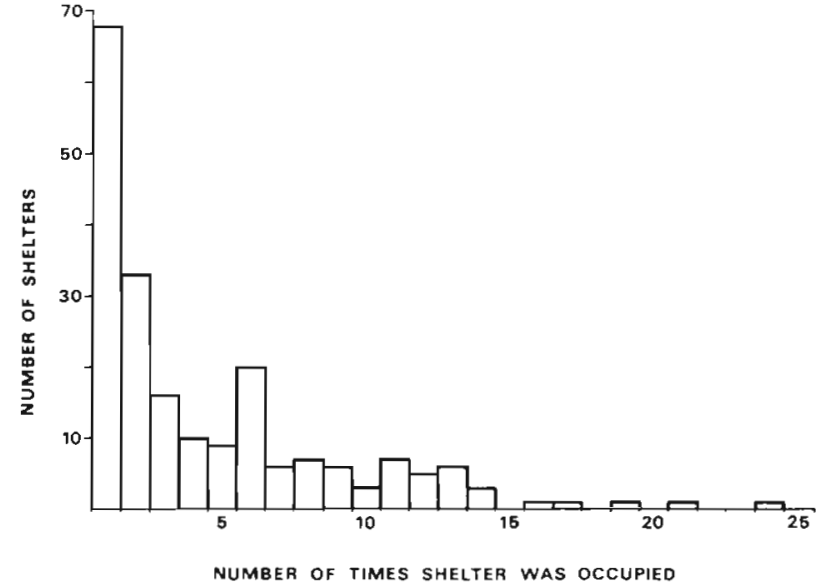

Fig. 2. Octopus bimaculatus. Shelter usage frequencies. Number of times each shelter was occupied between July 1977 and March 1979. Shelters occupied 4 or more times are considered to be suitable for residency. $(\mathrm{N}=204)$

Table 1. There is no correlation between octopus abundance and the estimated density of shelters ( $\mathrm{r}=$ 0.405 , n. s.). (The correlation is relatively high because of the extreme, i. e. more than $2 \mathrm{~s}$. d.'s away from the mean, shelter value for Site 15 ; without Site $15, \mathrm{r}=$ 0.024 .)

Shelters utilized by juvenile Octopus bimaculatus may be distinctly different from shelters used by adults. Because of their small size, juveniles can utilize much smaller shelters, and are usually found in small holes in the bedrock, kelp holdfasts, and empty shells (such as Cypraea spadicea, Astraea undosa, and Hinnites giganteus). At Bird Rock there is a great abundance of small shelters suitable for juveniles. Juvenile

Table 1. Octopus bimaculatus. Estimated shelter and octopus densities on 14 subtidal rocky reefs at Santa Catalina Island

\begin{tabular}{|ccc|}
\hline $\begin{array}{c}\text { Site } \\
\text { No. }\end{array}$ & $\begin{array}{c}\text { Shelter density } \\
\left(\text { No. } 10 \mathrm{~m}^{-2}\right)\end{array}$ & $\begin{array}{c}\text { Octopus density } \\
\left.\text { (No. } 100 \mathrm{~m}^{-2}\right)\end{array}$ \\
\hline 1 & 0.7 & 0 \\
2 & 4.7 & 0 \\
3 & 12.5 & 0 \\
4 & 8.5 & 0 \\
5 & 4.7 & 0 \\
6 & 8.7 & 0 \\
7 & 12.3 & 0.31 \\
8 & 23.0 & 0.45 \\
9 & 3.7 & 0.63 \\
10 & 10.0 & 0.63 \\
12 & 6.0 & 0.91 \\
13 & 14.3 & 1.11 \\
14 & 3.0 & 1.50 \\
15 & 29.0 & 1.67 \\
Mean (s.d.) & $10.1(7.9)$ & $0.52(0.59)$ \\
Bird Rock study site & \\
\hline
\end{tabular}

octopuses were rarely encountered at the Bird Rock study site despite a number of intensive searches, and virtually all suitable shelters were unoccupied.

\section{Length of Shelter Residence}

Nearly half of the Octopus bimaculatus population at the Bird Rock study site inhabited their shelter for a month or more, and $17 \%$ occupied the same shelter for more than 2 months (Fig. 3). Further observations on this population indicate that 3 octopuses remained in the same shelter for at least 5 months. Brooding octopuses, of course, remain in the same shelter from the time of egg laying until the death of the female several weeks after the eggs hatch, a total time of 1 to 5 months (Ambrose, unpubl.).

On the average, $25 \%$ of the octupuses spent less than 1 week in a shelter. Daily censuses indicate that many of these octopuses may switch shelters every day.

Observations on octopuses marked with garment tags confirmed that octopuses (at least those that were marked) found in the same hole on consecutive days were the same individuals. Observations of a tagged octopus during several dives within one 24 -h period verified that an octopus will leave its shelter, presumably to forage, and later return to re-occupy the same shelter.

One dye-marked octopus at the west end of Bird Rock was resighted twice in its original hole, suggesting continuous occupancy; the last resighting was $36 \mathrm{~d}$ after the octopus was first marked. A second octopus was resighted in its original hole $36 \mathrm{~d}$ after marking, but another octopus had occupied the hole in the interim. Other marked octopuses not found to reside in

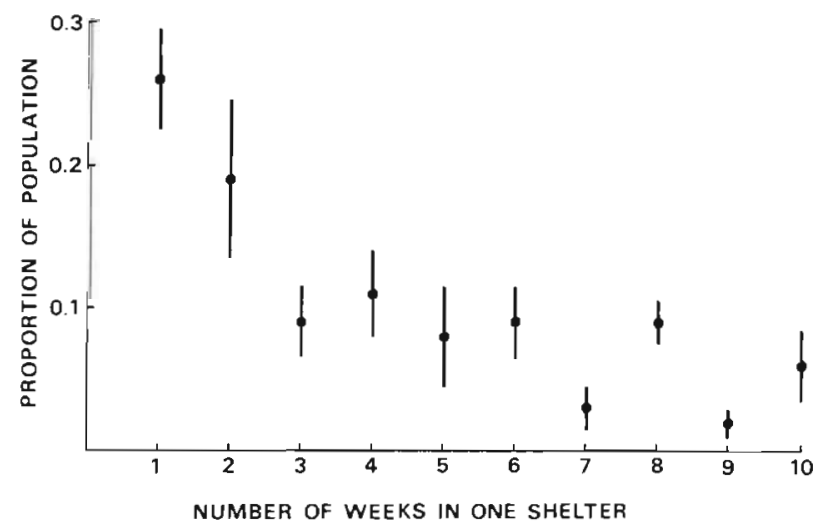

Fig. 3. Octopus bimaculatus. Length of shelter occupancy. Proportion of the population occupying shelters for different length runs number of consecutive censuses a shelter was occupied), excluding brooding fernales. Mean and standard deviation of 14 censuses taken nearly weekly over a period of 15 wk 
their original shelters (possibly due to the apparent trauma associated with marking) were located in the same general area. Two of these were found within a few meters of their original shelters 10 weeks after being marked.

\section{DISCUSSION}

Octopus bimaculatus occurs in a wide range of habitats and commonly occupies all types of shelters. Its strong association with shelters in bedrock and boulders is probably due to the selection of secure homes, for in addition to consisting of rock, shelters usually consist of enclosed spaces with only 1 entrance. Shelters found in sand were always next to a solid structure. The provision of ample and secure space seems to be a primary factor in the selection of a shelter. Beyond this minimal requirement, $O$. bimaculatus is opportunistic in its choice of shelter type.

Shelters are an essential resource that may limit the size of octopus populations. The release of thousands of cement pots in Hyogo Prefecture, Japan, resulted in a notable increase ( 0.75 ton per 40 pots released) in the catch of Octopus vulgaris (Rauchi and Matsumoto, 1954), implying that shelters were previously limiting. Mottet (1975) and Kanamaru and Yamashita (1967) suggest that the primary limiting factor on $O$. dofleini population size is the number of suitable shelters. Mottet (1975) further suggests that under normal conditions there is an overabundance of $O$. dofleini larvae that reach the early benthic stage, and that it may not be the mature population which is limited by the number of shelters but some smaller size classes.

Shelters that were suitable for inhabitation by Octopus bimaculatus were always in excess at the Bird Rock study site during this study. From June 1976 to April 1981 the censused $O$. bimaculatus population varied from 7 to 45 octopuses $(x=23.9$, s. $d .=11.6,55$ censuses; Ambrose, unpubl.). During these 5 years, the number of octopuses fluctuated below ca. 30, except for a 7 month period in 1978, when the population was 1.5 times as high as the 'normal' high (i. e. 45 vs. 30 ). Therefore, for nearly $90 \%$ of the time (52/59 months) over the past 5 years the octopus population has been considerably below its observed high. Even when the octopus population was at maximum size, there were twice as many suitable shelters (87) as octopuses. These data suggest that shelters are not limiting the $O$. bimaculatus population at Bird Rock.

If the number of shelters actually was limiting octopus population sizes, a close positive relationship between shelter density and octopus abundance would be expected. Data from the 14 sites indicate that there is no significant correlation between octopus and shelter densities. Most sites have greater shelter densities than the Bird Rock study site, but lower octopus abundances. In addition, there is no significant difference in shelter density between sites with octopuses and sites without octopuses (t-test, $\mathrm{t}=1.47, \mathrm{n}$. s.). Considering the variety of shelter types utilized by octopuses, these data suggest that shelters generally do not limit the size of Octopus bimaculatus populations in rocky habitats.

There may be some exceptions. One censused site had only 0.7 shelters $10 \mathrm{~m}^{-2}$, much lower than the Bird Rock study site. The zero density of octopuses at this site may have been related to the low availability of shelters. Shelters may also be limiting in areas such as sand habitats, resulting in a low density of octopuses. In these areas, man-made objects (cans, bottles, pipes, etc.) are heavily utilized as shelters, and probably allow a larger population size than would be possible in their absence. Man-made rock reefs at Santa Catalina have been rapidly colonized by octopuses ( $\mathrm{K}$. Behrents, pers. comm.; pers. obs.), allowing a greater number to live on the sand

The overabundance of shelters in rocky habitats is even more apparent for juvenile Octopus bimaculatus than for adults. The smaller shelters utilized by juveniles are extremely abundant. Juveniles are rarely found at the Bird Rock study site, and nearly all apparently suitable shelters are unoccupied. At the west end of Bird Rock, where juvenile octopuses could be reliably censused in kelp holdfasts, the greatest proportion of holdfasts occupied between July 1979 and June 1980 was 0.7 (Ambrose, unpubl.). Many holdfasts (mean proportion for 10 censuses $=0.26$, s. d. $=0.16$ ) contained more than 1 juvenile octopus. Since kelp holdfasts are not the only type of shelter suitable for juvenile octopuses, and even occupied holdfasts are available for additional octopuses, these data indicate that during this study shelters were in excess for juvenile $O$. bimaculatus.

In contrast to Mottet's (1975) suggestion that an overabundance of Octopus dofleini larvae reaching the early benthic stage results in the smaller size classes being limited by the number of shelters, shelters for juvenile $O$. bimaculatus were always in excess during this study. Furthermore, recruitment into the adult population at Bird Rock did not cause a shortage of available shelters. It appears that survival in larval and/or juvenile life stages was not sufficiently high to cause a shortage of shelters.

Marked Octopus bimaculatus generally stayed in the same area and moved only short distances when they changed shelters. Kayes (1974) found that $O$. vulgaris movements were mostly confined to an area of $4000 \mathrm{~m}^{2}$ (about 4 times the area of the Bird Rock study 
site). Marked O. cyanea moved less than $30 \mathrm{~m}$ in 15 to $74 \mathrm{~d}$ after their release (Van Heukelem, 1973). $O$ cyanea and $O$. vulgaris have been oberved to move their homes to shelters only a short distance away (respectively Van Heukelem, 1966; Altman 1967).

Marked Octopus vulgaris released off the coast of Japan, however, have travelled up to $50 \mathrm{~km}$ in $40 \mathrm{~d}$ (Itami, 1964). These octopuses may have been involved in seasonal migrations. Mediterranean $O$. vulgaris move to deeper areas in autumn and winter and return to shallow water in spring (Mangold-Wirz, 1963; Cousteau and Diole, 1973). $O$. dofleini in the northern Pacific Ocean, and $O$. rubescens off the California coast also migrate seasonally (respectively Mottet, 1975; Hochberg, pers. comm.). During migrations, $O$. dofleini individuals may move $4 \mathrm{~km}$ in 1 day (Kanamaru and Yamashita, 1967). I found no evidence of seasonal migrations of $O$. bimaculatus during this study.

Although many of the Bird Rock Octopus bimaculatus changed shelters frequently, most maintained what could be called permanent shelters. I could not discern any difference between 'permanent' and 'transient' octopuses, nor between their shelters (although occasionally a transient octopus was found in an obviously unsuitable shelter). In fact, shelters which were at one point occupied for many consecutive weeks were at another time occupied for only a week at a time.

Octopus bimaculatus may occupy shelters for a longer period of time ( 5 months or more) than previously reported for other octopuses. O. cyanea apparently may occupy the same shelter for 3 to 5 weeks (Van Heukelem, 1966; Yarnall, 1969; longer periods are possible, since Van Heukelem's observations were terminated prematurely). Studies of $O$. vulgaris in the Mediterranean Sea suggest that it may occupy shelters for up to 4 weeks (Altman, 1967; Kayes, 1974).

The existence of a population comprised mainly of permanent residents has important implications for the ecology of Octopus bimaculatus. Mating and agonistic behavior may be influenced by familiartiy between participants. A non-transient octopus population could result in a different pattern or intensity of resource utilization than a migratory or purely transient population. Since foraging activity would be restricted, predation pressure might be more intense near octopus shelters. Nelson and Vance (1979) and Vance (1979) have suggested this effect for the urchin Centrostephanus coronatus, where shelter fidelity may lead to intense grazing pressure around urchin shelters. With an organism such as octopus, permanent residence could lead to more efficient predation due to the ability to learn patterns of resource availability within an area. Learning might also result in greater use of a preferred but rare prey species if prey occurrence is predictable (at least over a short time). The frequent utilization of crabs, the chiton Stenoplax conspicua, and the snail Tegula aureotincta, all preferred but relatively rare prey species (Ambrose, unpubl.), might be due in part to learning by $O$. bimaculatus.

Acknowledgements. I thank Bobette Nelson and Eric Hochberg for assistance throughout this study. J. A. Coyer, F. G. Hochberg, B. V Nelson, J. S. Pearse and R. J. Schmitt critically reviewed the manuscript. Bobette Nelson assisted in all aspects of the field work. This research was supported in part by a grant from the Lerner Fund for Marine Research of the American Museum of Natural History. This paper is contribution No. 52 from the Catalina Marine Science Center.

\section{LITERATURE CITED}

Altman, J. S. (1967). The behavior of Octopus vulgaris Lam. in its natural habitat: a pilot study. Underwater Assoc. Rep. 1966-67, pp. 77-83

Cousteau, J., Diole, P. (1973). Octopus and squid, Doubleday, New York

Fawcett, M. (1979). The consequences of latitudinal variation in predation for some marine intertidal herbivores. $\mathrm{Ph} . \mathrm{D}$. dissertation, Univ. Calif., Santa Barbara

Fotherington, N. (1974). Trophic complexity in a littoral boulder-field. Limnol. Oceanogr. 19: 84-91

Hochberg, F. G., Couch, J. A. (1971). Biology of cephälopods. In: Miller, J. W., Vanerwalker, J., Walier, R. A. (eds.) Scientists-in-the-sea. U.S. Dept. Interior, Washington, D. C., pp. $221-228$

Hochberg, F. G., Fields, W. G. (1980). Cephalopoda: the squids and octopuses, Chapter 17 In: Morris, R., Abbott, D., Haderlie, E. (eds.) Intertidal invertebrates of California. Stanford Univ. Press, Stanford (in press)

Itami, K. (1964). Marking and release study in the Octopus. Aquaculture 12: 119-125 (in Japanese - cited by Van Heukelem, 1973)

Kanamaru, S., Yamashita, U. (1967). The octopus mizudako (Part 1). Hokkaido Engan Gyogyo Shigen Chosa Narabi Ni Gyogyo Keiei Shiken Hokokusho 1961-1965, Chapter 23. pp. 238-249 (in Japanese - cited by Mottet, 1975)

Kayes, E. J. (1974). The daily activity pattern of Octopus vulgaris in a natural habitat. Mar. Behav. Physiol. 2: $337-343$

Legac, M. (1969). Some observations on the building up of hiding places by the Octopus vulgaris Lam. in the channel region of the North-eastern Adriatic. Thalassia jugosl. 5: 193-198

MacGinitie, G. E. (1938). Notes on the natural history of some marine animals. Am. Midl. Nat. 19: 207-219

Mangold-Wirz, K. (1963). Biologie des Cephalopodes benthiques et nectoniques de la Mer Catalone. Vie Milieu 13 (Suppl.): 1-285

Mottet, M. G. (1975). The fishery biology of Octopus dofleini. Wash. Dept. fish. Tech. Rep. 16: 1-39

Nelson, B. V., Vance, R. R. (1979). Diel foraging patterns of the sea urchin, Centrostephanus coronatus, as a predator avoidance strategy. Mar Biol. 51: 251-258

Rauchi, M., Matsumoto, A. (1954). On the protection of spawner octopus (Polypus vulgaris Lamarck) in Hyogo Prefecture. Bull. Soc. Sci. Fisheries 20: 479-482 (cited by Mottet, 1975) 
Schmitt, R. J. (1979). Interactions between predators and secondarily preferred prey: consequences of dissimilar anti-predator defenses in a marine subtidal community. Ph. D. dissertation, Univ. Calif., Los Angeles

Van Heukelem, W. F. (1966). Some aspects of the ecology and ethology of Octopus cyanea Gray. M. S. thesis, Univ. of Hawaii

Van Heukelem, W F. (1973). Growth and life-span of $O$ cyanea (Mollusca: Cephalopoda). J. Zool. (Lond.) 196: 299-315

Vance, R. R. (1979). Effects of grazing by the sea urchin,
Centrostephanus coronatus, on prey community composition. Ecology 60: 537-546

Wells, R. A. (1980). Activity pattern as a mechanism of predator avoidance in two species of acmaeid limpet. J. exp. mar Biol. Ecol. 48: 151-168

Wolterding, M. M. (1971). The rearing and maintenance of Octopus briareus in the laboratory, with aspects of their behavior and biology. M.S. thesis, Univ. Miami

Yarnall, J. L. (1969). Aspects of the behavior of Octopus cyanea Gray. Anim. Behav. 17: 747-754

This paper was presented by Professor J. S. Pearse; it was accepted for printing on August 21, 1981 